\title{
UNDER WHICH CONDITIONS IS CARRIER COOPERATION POSSIBLE? A CASE STUDY IN A SEVILLE MARKETPLACE
}

\author{
Jesús MUÑUZURI*, Alejandro ESCUDERO-SANTANA, Pablo APARICIO-RUIZ \\ Dept of Industrial Organisation and Business Management, University of Seville, Spain
}

Received 13 June 2016; revised 12 September 2016, 23 November 2016; accepted 20 January 2017

\begin{abstract}
The high volume of traffic originates two well-known problems in many cities: congestion and pollution. In recent years, a social phenomenon is emerging cooperation. This work is aimed at evaluating the circumstances under which transport cooperation is possible between different stakeholders operating in the same geographical area. To this end, a double survey process was conducted in a marketplace situated in the Seville City (Spain) centre. The first survey was designed to know the characteristics of the retailers and their preferences with respect to cooperation and regulations. A relational analysis between retailer features and their willingness to cooperate was carried out. After analysing the motivations for non-cooperation, a mixed proposal was designed and surveyed. Although the research was limited to a marketplace, the relevant data gathered from this double survey process highlights some implications: (a) the importance of personal relations in retailer cooperation; (b) a high volume of freight and the use of vans as on-street warehouses appear as significant motivations for non-cooperation; (c) forcing changes in the statu quo encourages cooperation.
\end{abstract}

Keywords: city logistics, city transport, cooperation, regulation, stakeholder group.

\section{Introduction}

Urban goods distribution is indispensable for the economic development of cities. However, the distribution of those products contributes to the worsening of the traffic congestion and pollution (Muñuzuri et al. 2005). Fresh food marketplaces are not an exception, with typical congestion problems and lack of parking areas around their locations. Therefore, different measures should be planned by all the involved stakeholders; one of them is cooperation in the distribution process.

Implementing urban freight initiatives represents an alteration of the balance in urban space and/or economic resources among the different groups competing for it: drivers, residents, shop owners, pedestrians, transit system operators, local administrators, etc. Thus, it is recommendable to assess the point of view of every stakeholder group, before developing any possible policies (Österle et al. 2015). While the main concerns of the city government are the welfare of the citizens (parking areas availability, low level of traffic, etc.) and environmental aspects (pollution and noise), retailers have other worries, such as low taxes, flexibility of deliveries, parking areas near their shops, etc. Obviously, there is sometimes a clash of interests that must be addressed (Lindholm, Browne 2013).
Although there exist different works related to cooperation in urban distribution (Dablanc et al. 2011; Lindholm, Browne 2013; Österle et al. 2015), none is focused on this type of facility (marketplace), where retailers often have common providers, or whose providers are located at a common facility (like a fresh food wholesale market).

The purpose of this article is to find constructive ways of collaboration in the context of a heterogeneous marketplace with multiple types of products, roles, and conflicting objectives. In general, local authorities have problems to regulate and organize distribution in order to make it more efficient. Thus, our objective is to know under which conditions this cooperation is possible and to determine whether certain urban freight initiatives could contribute to alleviate the daily delivery process at a fresh food marketplace. This study is carried out in the city of Seville (Spain). The following sections present: (a) the description of the problem; (b) a review of related works; (c) the research method, where we present both the different proposed measures and the development of the survey process; (d) an analysis and discussion of the achieved results; (e) the conclusions and references.

*Corresponding author. E-mail: munuzuri@us.es 


\section{Background}

Fresh Food Marketplaces consist of large buildings containing multiple stands belonging to independent retailers who sell commonly fresh food, including fish, meat, fruit and vegetables. In Spain, they constitute a traditional type of premises where a group of retailers are merged in one single building.

These buildings are usually located in traditional areas of the city, so their freight delivery necessities frequently face problems related to accessibility and parking. Jaller et al. (2013) discuss different strategies for the management of freight parking demand developed by governmental agencies and other organizations, stressing that the main challenge in urban freight deliveries is often the availability of parking spaces, with many drivers attempting to find curb space to pick up or deliver their supplies. The authors emphasize that the challenge of looking for a parking slots is even greater in old cities where there are narrow streets originally designed for non-motorized societies. The lack of parking policies or solutions in these areas has resulted in the current scenario: frustrated drivers circling the block or double-parking.

These premises are usually located in dense commercial areas, which further aggravates parking problems. The majority of fresh food retailers operating in marketplaces are aware of these problems. In fact, the distribution of goods spends most of the time in the final stage, due to the high level of congestion on the available loading zones. Modern Fresh Food Marketplaces have specific parking facilities available for the retailers and loading/unloading operations, as do the new marketplace in the city of Huelva or the restored marketplace of Triana in Seville, which have incorporated an underground parking lot. However, old marketplaces (most of them) usually present a shortage of car park or spaces destined for pickup and delivery. Muñuzuri et al. (2005) underline the correlation between congestion levels and freight delivery conditions. In addition, it points to the lack of specific infrastructure aimed at facilitating access, parking, loading, unloading and delivery of goods as one of the main problems faced by city logistics stakeholders.

As a good example of this type of marketplaces, we conducted our case study at Feria Fresh Food Marketplace, located in the historical centre of the city of Seville, the most populous town in the South of Spain, with around 700000 inhabitants. Besides, its historical centre is the most extensive of Spain with over $4 \mathrm{~km}^{2}$. Figure 1 shows a map of the city, where the shaded area is the historical centre and point $A$ is the marketplace location.

Although the marketplace offers mainly fresh food such as meat, fish, fruit and vegetables, there is also a large variety of other types of shops selling products like fresh pasta, canned food, drinks, ice cream or sushi. The distribution of commercial activities is shown in Table 1. Since the Feria Marketplace is mainly destined to fresh food, the most important supply centre is MercaSevilla, a wholesale centre located $7 \mathrm{~km}$ away from the marketplace (point B in Figure 1).

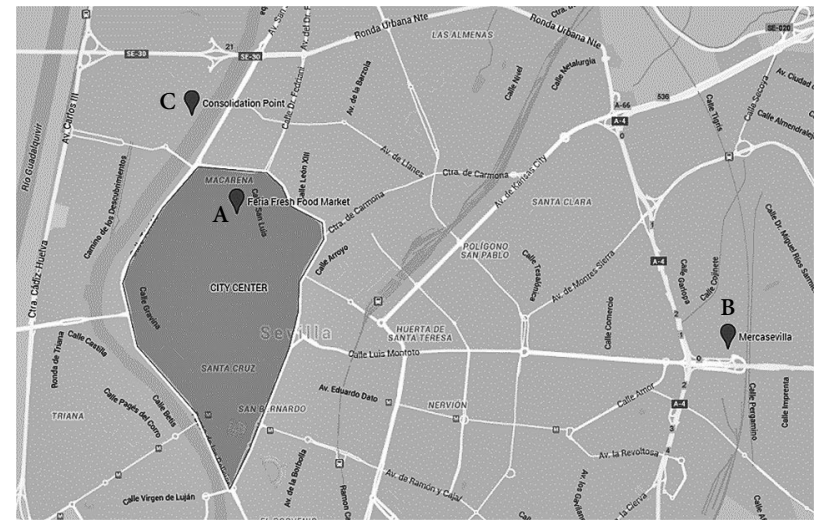

Figure 1. Location of Feria Marketplace (point A) in Seville

Due to its location, the accessibility of the Feria Marketplace is not easy, and the parking areas are limited. It is accessible by road only from one side, where the loading zones are located. In Figure 2, shaded vehicles identify these zones with capacity for 5 vehicles. These marketplace loading zones are reserved for retailers during the 7:00 and 11:00 am. During the afternoon hours, they are reserved for the local waste collection company. Furthermore, two additional loading zones in the nearby area for seven and three vehicles respectively can be used to service the marketplace.

Table 1. Distribution of commercial stalls in Feria Marketplace

\begin{tabular}{|l|c|}
\hline \multicolumn{1}{|c|}{ Type of commerce } & No of stalls \\
\hline Meat $(\mathrm{M})$ & 5 \\
\hline Pork products (PP) & 2 \\
\hline Fruit and vegetables (FV) & 10 \\
\hline Fish (F) & 8 \\
\hline Chicken (C) & 3 \\
\hline Others (O) & 17 \\
\hline
\end{tabular}

In the case of the Feria Marketplace, the efficiency and reliability of deliveries, as well as the availability of parking space is a concern for both carriers and receivers. The narrow streets in the area, the access time windows and the delivery frequencies imposed by supply chain considerations are the main transport-related worries for these stakeholder groups. Conversations with retailers and the analysis of the area led us to conclude that:

- almost all the delivery activities take place on a daily basis, increasing the parking problems, especially during the 7:00...9:00 am period;

- the opinions with respect to the difficulty of parking in the reserved spaces are unanimous;

- the options are either to double-park, which is not always feasible in a one-lane street with plenty of car and bus traffic, or to find a parking space away from the marketplace, with the subsequent difficulties for the final delivery. 


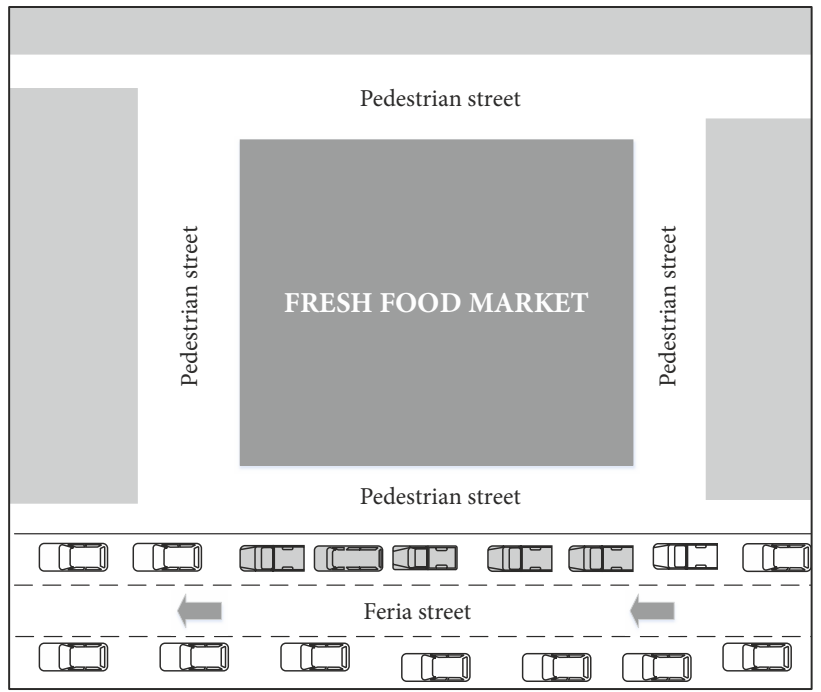

Figure 2. Loading zone in front of the Feria Marketplace

Thus, the marketplace requires a solution to improve this situation. In the logistics of marketplace deliveries, retailers can choose to seek cooperation with others to exploit synergies (Razzaque, Sheng 1998). In our case, the preliminary consultation with all the stakeholders about this problem pointed out two possible solutions: cooperation and regulation.

\section{Literature review}

Cooperation in transportation is based on the shared use of vehicles for freight distribution, requiring a previous agreement among the stakeholders involved. As indicated by Chen et al. (2012), urban cooperative deliveries can significantly reduce congestion and emissions by consolidating deliveries of goods at a facility outside urban areas. The implementation of this measure would result in a reduction of the congestion of loading zones. A similar problem is developed by Marcucci et al. (2011) and Marcucci, Gatta (2014), for deliveries to non-food shops in Rome. In Gammelgaard (2015), an urban consolidation centre is proposed to achieve these objectives.

Nowadays, the distribution chains of several retailers tend to incorporate higher degrees of cooperation. This fact has been accelerated thanks to the current development of information technologies, which allow more transparency and therefore closer collaboration among retailers and carriers. Consequently, it is possible to reduce vehicle kilometres and to improve their loading rates (Verlinde et al. 2012). Gonzalez-Feliu et al. (2013) complete a first classification of vertical and horizontal collaboration in urban logistics, and propose an assessment of horizontal collaborations for urban distribution. Pomponi et al. (2015) present a theoretical framework for the design and development of horizontal collaboration in the supply chain context.

The establishment of effective cooperative measures is likely to improve many aspects of urban distribution
(Saeed 2013). Along this line, the importance of a framework to facilitate the interaction between stakeholders has been highlighted in the literature (Österle et al. 2015), stressing the need for local authorities to play a major role (Lindholm, Browne 2013).

The EC (2001) defines horizontal cooperation as "concerted practices between companies operating at the same level(s) in the marketplace". These can be either competing or unrelated companies that share private information, facilities or resources to reduce costs or improve service. Bengtsson and Kock (1999) identify four types of horizontal relationships. As it will be outlined below, the measure of cooperation considered in this paper is associated with the first type, where the cooperative relationships do not include any economic exchanges and the goals of the companies are stipulated independently. Additionally, the authors define other types: regulated cooperation (tight bonds exist between companies that define and pursue common goals), basic competition (the same or comparable suppliers and target the same group of clients), and coopetition (cooperation takes place for non-core activities, while competition remains unchanged for core activities).

The literature shows different examples of horizontal cooperation in logistics, like joint route planning and purchasing groups (Jaržemkis 2007). Horizontal cooperation is based on identifying and exploiting win-win situations among shops that are active at the same level of the supply chain in order to increase performance. These companies can be suppliers, retailers or receivers (customers). The first goal of the transportation cooperation is to reduce transportation costs. A severe competition in marketplaces and heightened customer expectations have resulted in reductions in the profit margins. For this reason, there is a strong incentive to decrease the costs of non-value-adding activities. Consequently, the trade is experiencing a fundamental reorganization and since the potential of internal logistics optimization is almost completely exploited, attention has shifted to better managing external relations in the supply chain, establishing joint efforts to develop cooperation, the customization of the logistics solution, and a fair sharing of benefits and risks (Skjoett-Larsen 2000).

Cruijssen et al. (2007) present a review of horizontal cooperation. This type of cooperation requires inter-firm coordination, a concept that is well studied in organizational literature. They review the opportunities provided by horizontal cooperation and relate them with costs, productivity, customer service, marketplace position and others. The impediments and threats posed by horizontal cooperation are identified by: the partners, determining and dividing the gains, negotiation, and coordination. The facilitators of horizontal cooperation are related to information sharing, incentive alignment, relationship management and contracts, information technology and others. In Gonzalez-Feliu and Salanova (2012), several collaborative urban freight transportation systems are defined. After the simulation and analysis, they observe collaboration has some advantages, but it is not always the 
best solution for each criterion. Besides, other two appreciations are presented: first, the solution preferred by one operator does not necessarily coincide with the best solution for the system; and second, collaborative strategies present risks that have to be evaluated. Pan et al. (2014) apply pooling cooperation to the collection of small and medium-sized western France food suppliers serving the same retail chain, in order to demonstrate the efficiency (cost and $\mathrm{CO}_{2}$ ) of the pooling system.

Regarding regulation measures, Muñuzuri et al. (2012) present the picture of the current scenario and the typical regulation schemes in Spain, analysing the reasons for failure of the system and the possible efforts (relatively cheap and easy to implement) that could be undertaken towards the improvement of urban freight deliveries. Mingardo et al. (2015) analyse the evolution of parking policy in Europe, including different aspects of parking regulations and their generic evolution. These regulations usually generate controversy; while the perception of this policy was positive in the case of Toledo, the shop owners in Mérida were clearly against it, believing that it discouraged sales rather than promoting them, since the cost to be assumed by the final customers was now increased by the parking fee amount.

\section{Methodology}

With the purpose of identifying elements that may facilitate or hamper the cooperation in marketplaces, we conducted a double survey process in the Feria marketplace. This paper focuses on survey research to contribute to the general body of knowledge in a particular area of interest, namely the circumstances under which cooperation is possible among the stakeholders of a fresh food marketplace. Previously to the in-depth survey process, preliminary and informal talks were held with all the stakeholders, with the objective of achieving a global view.

Survey research is a method used to perform empirical researches in Operation Management (Karlsson 2008) and widely used in consultation related to cooperation initiatives (Dablanc et al. 2011; Österle et al. 2015). Due to the characteristics of the scenario, we designed a twostage survey: in a first phase, we explored acceptability and availability to collaborate. Besides, this survey provided information about the characteristics of the retailers. Forza (2008) defines this preliminary step as "exploratory survey research". The objective is to provide a more indepth knowledge about the scenario in order to analyse collaborative solutions, motivations, difficulties and limits regarding several types of actions. A set of attributes can be derived from three main sources: literature survey, previous quantitative studies and focus group meetings with relevant expert stakeholders. The possible solutions are explored via interviews and conversations. In the second phase, after analysing the first phase results, a measure is induced and a second survey is implemented. Forza (2008) defines this methodology as "confirmatory survey research", which takes place when the knowledge of a phenomenon has been articulated in a theoretical form. In this case, the data collection process is carried out with the specific aim of testing the adequacy of a new proposal. This was conducted to study the acceptability and deployment conditions of this measure. Finally, we assessed the suitability of this measure empirically. A more extensive explanation of this double survey process is provided below.

Following indications from the local authorities, any solution to be implemented in the Feria Marketplace should be supported by the majority of marketplace retailers. Initially, two options were proposed to them: (a) cooperation in transportation and logistics, which was our primary objective; (b) the introduction of regulation enforcement, with the introduction of parking meters, which was suggested by some of the shop owners during the preliminary talks.

Two cooperation possibilities (Figure 3) were presented to the retailers in the Marketplace. First, the possibility of establishing a direct consolidation point in MercaSevilla, the local wholesale market for fresh food, which is the main supply centre for this Marketplace. Second, the creation of a consolidation point in the outskirts of the city centre, around $2.5 \mathrm{~km}$ away from the premises (point $C$ in Figure 1). These solutions follow a similar approach to the one found in Gammelgaard (2015).

The introduction of parking meters would be aimed at improving the accessibility of both customers and retailers to the marketplace. Since the users of parking spaces would have to pay for using it, this measure should result in higher levels of rotation in the parking area.

Both measures were tested in parallel, so we could compare the result obtained. Besides, the retailers were asked with an open question about other possible measures. In this first round of surveys (made in the first months of 2014), we also analysed the characteristics of the retails.

The results of these surveys is shown in Table 2. Each row represents a retailer surveyed (a total of 39). They were grouped according to their activity: group 1 repre-

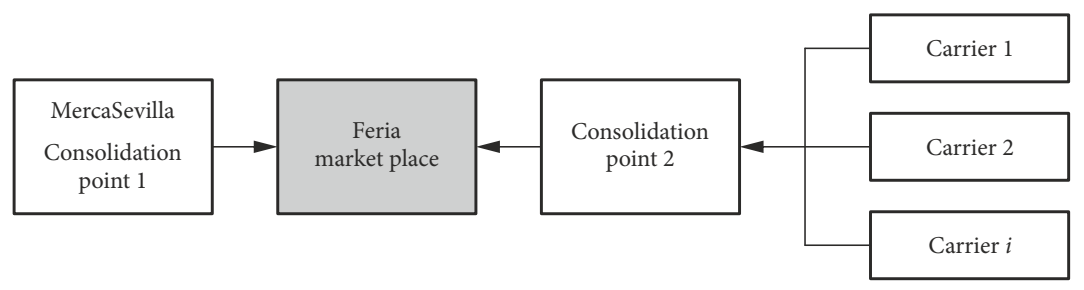

Figure 3. Proposed cooperative schemes 
Table 2. Surveys to retailers

\begin{tabular}{|c|c|c|c|c|c|c|c|c|c|c|c|c|c|}
\hline & \multicolumn{6}{|c|}{ Retailer characteristic } & \multicolumn{3}{|c|}{ Cooperation } & \multicolumn{3}{|c|}{ Regulation } & \multirow[b]{2}{*}{ 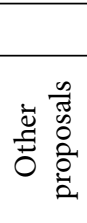 } \\
\hline Group & 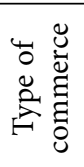 & 奇 & 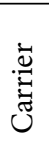 & 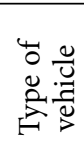 & 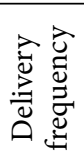 & 兽 & $\stackrel{\mathscr{V}}{\sim}$ & $\stackrel{\circ}{z}$ & 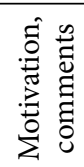 & 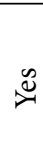 & $\stackrel{2}{z}$ & 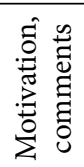 & \\
\hline \multirow{9}{*}{ Group 1} & FV & $\mathrm{M}$ & $\mathrm{O}$ & ST & $\mathrm{D}$ & $\mathrm{H}$ & & $x$ & 1,2 & & $x$ & 7 & $\mathrm{~A}$ \\
\hline & FV & $\mathrm{M}$ & $\mathrm{O}$ & $\mathrm{V}$ & $\mathrm{D}$ & $\mathrm{H}$ & & $x$ & $1,2,3$ & & $x$ & 7 & A \\
\hline & FV & $\mathrm{M}$ & $\mathrm{O}$ & $\mathrm{V}$ & $\mathrm{D}$ & $\mathrm{H}$ & & $x$ & 1,2 & $x$ & & & $\mathrm{~B}$ \\
\hline & FV & $\mathrm{M}$ & $\mathrm{O}$ & $\mathrm{V}$ & $\mathrm{D}$ & $\mathrm{H}$ & & $x$ & 1,2 & & $x$ & 9 & \\
\hline & FV & $\mathrm{M}$ & $\mathrm{O}$ & $\mathrm{V}$ & $\mathrm{D}$ & $\overline{\mathrm{H}}$ & & $x$ & $1,2,4$ & $x$ & & 8 & \\
\hline & FV & $\mathrm{M}$ & $\mathrm{O}$ & $\mathrm{V}$ & $\mathrm{D}$ & H & & $x$ & 4,5 & & $x$ & 9 & \\
\hline & FV & $\mathrm{M}$ & $\mathrm{O}$ & $\mathrm{V}$ & $\mathrm{D}$ & $\overline{\mathrm{H}}$ & & $x$ & 1,2 & $x$ & & & \\
\hline & FV & $\mathrm{M}$ & $\mathrm{O}$ & $\mathrm{V}$ & $\mathrm{D}$ & $\overline{\mathrm{H}}$ & & $x$ & 1,2 & & $x$ & & \\
\hline & FV & $\mathrm{M}$ & $\mathrm{O}$ & $\mathrm{V}$ & $\mathrm{D}$ & $\overline{\mathrm{H}}$ & & $x$ & 1,2 & & $x$ & & $\mathrm{~A}$ \\
\hline \multirow{9}{*}{ Group 2} & F & $\mathrm{M}$ & $\mathrm{O}$ & $\mathrm{V}$ & $\mathrm{D}$ & $\mathrm{M}$ & $x$ & & + & $x$ & & 8 & \\
\hline & $\bar{F}$ & M & $\mathrm{O}$ & $\mathrm{V}$ & $\mathrm{D}$ & M & & $\times$ & & $x$ & & & \\
\hline & $\mathrm{F}$ & M & $\mathrm{O}$ & $\mathrm{V}$ & D & M & $x$ & & 4 & $x$ & & 8 & \\
\hline & $\mathrm{F}$ & $\mathrm{M}$ & $\mathrm{O}$ & V & $\mathrm{D}$ & M & $x$ & & & & $\times$ & 10 & \\
\hline & $\mathrm{F}$ & $\mathrm{M}$ & $\mathrm{O}$ & $\mathrm{V}$ & $\mathrm{D}$ & $\mathrm{M}$ & $x$ & & + & $x$ & & & $\mathrm{C}$ \\
\hline & $\mathrm{F}$ & M & $\mathrm{O}$ & $\mathrm{V}$ & $\mathrm{D}$ & $\mathrm{M}$ & $x$ & & & $x$ & & & \\
\hline & $\mathrm{F}$ & M & $\mathrm{O}$ & $\mathrm{V}$ & $\mathrm{D}$ & $\mathrm{M}$ & & $x$ & 5 & $x$ & & & \\
\hline & $\mathrm{F}$ & $\mathrm{M}$ & $\mathrm{O}$ & $\mathrm{V}$ & $\mathrm{D}$ & $\mathrm{M}$ & $x$ & & & $x$ & & & \\
\hline & $\mathrm{O} 1$ & $\mathrm{M}$ & $\mathrm{O}$ & $\mathrm{C}$ & $\mathrm{AD}$ & $\mathrm{L}$ & $x$ & & 4,6 & $x$ & & & $\mathrm{~A}$ \\
\hline \multirow{9}{*}{ Group 3} & $M$ & M & $\mathrm{O}$ & $\mathrm{V}$ & $\mathrm{D}$ & $\mathrm{M}$ & & $x$ & & & $\bar{x}$ & 10 & \\
\hline & $\mathrm{M}$ & $\mathrm{S}$ & $\mathrm{S}$ & $\mathrm{D}$ & $\mathrm{D}$ & - & & $x$ & & $x$ & & 7 & \\
\hline & $\mathrm{M}$ & $\mathrm{M}$ & $\mathrm{S}$ & $\mathrm{V}$ & $\mathrm{AD}$ & - & & $x$ & 4 & $x$ & & & \\
\hline & $M$ & $\mathrm{~S}$ & $\mathrm{~S}$ & $\mathrm{~V}$ & $\mathrm{AD}$ & - & & $x$ & & 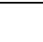 & & & \\
\hline & PP & $S$ & $S$ & V & $\mathrm{D}$ & - & & $x$ & 4 & $x$ & & 8 & \\
\hline & PP & 1 & S & V & $1 \mathrm{~W}$ & - & & $x$ & & $x$ & & 11 & \\
\hline & $\mathrm{C}$ & 1 & $\mathrm{~S}$ & $\mathrm{~V}$ & $\mathrm{D}$ & - & & $x$ & 4 & $x$ & & 8 & \\
\hline & $\mathrm{C}$ & $S$ & $\mathrm{~S}$ & ST & $\mathrm{D}$ & - & & $x$ & & & $x$ & & \\
\hline & $\mathrm{C}$ & $\mathrm{M}$ & $\mathrm{B}$ & $\mathrm{C}$ & $1 \mathrm{~W}$ & $\mathrm{~L}$ & & $x$ & & & $\bar{x}$ & & \\
\hline \multirow{5}{*}{ Group 4} & $\mathrm{O} 2$ & $S$ & $\mathrm{~S}$ & $F$ & $2 \mathrm{~W}$ & - & & $x$ & 6 & $x$ & & 8 & \\
\hline & O3 & 1 & $\mathrm{~B}$ & $\mathrm{C}$ & $1 \mathrm{~W}$ & $\mathrm{M}$ & & $x$ & 6 & $x$ & & & \\
\hline & $\mathrm{O} 4$ & $M$ & $\mathrm{~S}$ & $\mathrm{~V}$ & $\mathrm{D}$ & - & & $x$ & 6 & $x$ & & 8 & \\
\hline & O5 & $S$ & B & $\mathrm{D}$ & $\mathrm{D}$ & $\mathrm{L}$ & & $x$ & 6 & & & & \\
\hline & O6 & 1 & $S$ & $\mathrm{C}$ & $\mathrm{AD}$ & - & & $x$ & 6 & $x$ & & 11 & \\
\hline \multirow{3}{*}{ Group 5} & O7 & $S$ & $\mathrm{~S}$ & $\mathrm{~V}$ & $2 \mathrm{~W}$ & - & & $x$ & 6 & & $x$ & & A \\
\hline & $\mathrm{O}$ & 1 & $\mathrm{~B}$ & $\mathrm{C}$ & $2 \mathrm{M}$ & $\mathrm{L}$ & & $x$ & 6 & $x$ & & & \\
\hline & O8 & 1 & $\mathrm{O}$ & $\mathrm{V}$ & $2 \mathrm{~W}$ & $\mathrm{~L}$ & & $x$ & 6 & $x$ & & 7 & \\
\hline \multirow{4}{*}{ Group 6} & O9 & $\mathrm{S}$ & $\mathrm{S}$ & $\mathrm{S}$ & $1 \mathrm{M}$ & - & & $x$ & 6 & $x$ & & 7,8 & \\
\hline & $\mathrm{O} 10$ & $S$ & $\mathrm{~S}$ & $\mathrm{~V}$ & $2 \mathrm{~W}$ & - & & $x$ & 6 & $x$ & & 7 & \\
\hline & O11 & 1 & $\mathrm{~S}$ & $\mathrm{~V}$ & $2 \mathrm{M}$ & - & & $x$ & 6 & $x$ & & 7,8 & \\
\hline & O12 & 1 & $\mathrm{O}$ & $\mathrm{C}$ & $3 \mathrm{~W}$ & $\mathrm{M}$ & $\times$ & & 6 & & $x$ & 9 & \\
\hline
\end{tabular}

sents fruit and vegetables traders (FV); group 2 includes fish traders (F) and similar activities, like sushi traders (O1); group 3 is formed by the meat-based products traders, including meat $(\mathrm{M})$, pork products $(\mathrm{PP})$ and chicken $(\mathrm{C})$; the rest of fresh product retailers are merged in group 4 (O2-O6: bakery, ice-cream shop, take away food, fresh pasta, flower shop), group 5 (O7-O8: oils and liquors and canned food) and group 6 (O9-O12: stores of kitchenware, electricity, shoes and pets), all of them associated to non-perishable products. The columns contain the group and the characteristics of every retailer, their opinion with respect to the measure of cooperation, their opinion regarding the use of parking meters, and any additional comments or suggestions.

Dealing with the characteristics of every retailer, 6 aspects were evaluated: the type of commerce (classified according Table 1), the origin of the freight (1 - one store; $\mathrm{S}$ - several stores; $\mathrm{M}$ - MercaSevilla), the type of carrier (O - own transport; $\mathrm{S}$ - supplier; B - both), the type of vehicle used (V - van; ST - small truck; C - car; $\mathrm{S}$ - sev- 
eral of them), the frequency of delivery (D - daily, AD almost daily; $\times \mathrm{W}-\times$ days a week; $\times \mathrm{M}-\times$ days a month) and the volume of freight that they transport $(\mathrm{H}-$ high; $\mathrm{M}$ - medium; L - low).

The results show that a significant number of the marketplace retailers transport their own goods, which means that they are directly affected by the scarcity of parking space. Most of the retailers collect their goods at MercaSevilla, typically using either large or small vans.

Their opinions with respect to the proposed cooperation initiative are mainly negative, with a generalized lack of support for the scheme. The motivations expressed for this opposition are: (1) the vehicle is completely full with their own products; (2) the vehicle is used as an on-street warehouse; (3) different requirements in packaging management; (4) desire for independence in terms of schedules, frequency, etc.; (5) the disagreement between retailers; (6) the belief that cooperation is impossible, due to the particularity of their shops. The correspondence between these opinions and the retailers expressing them is shown in Table 2.

The main support for this policy came from the fish retailers, some of which are in fact operating the only existing cooperation case in the Marketplace (+ in Table 2). They did mention to us that cooperative deliveries were common years ago among fish retailers, but they disappeared when it became easier for them to own and manage their own vehicle.

With respect to the possibility of incorporating parking meters in the loading zones, it has a better support, despite the fact that one third of the surveyed retailers are clearly against it. Those in favour consider that this policy might improve rotation in the parking spaces (7) and the affluence of customers to the marketplace (8), while those against it stress that it would only represent additional costs (9). Other retailers are satisfied with the current situation (10), and for others, their election depends on the final implementation (11).

In relation to parking meters, an important consideration is the fact that the arguments of retailers in favour of this measure are focused on avoiding the occupation of the loading zones with vehicles used as on-street warehouses; however, some members of group 1 stated their clear preference for the current scenario.

Through the open questions in the survey, 3 suggestions were proposed by the retailers:

- new loading/unloading areas in the surrounding pedestrian streets;

- areas to park the vehicles after the loading/unloading operations have been completed, thus freeing the loading zones;

- segmentation of loading zones by activity.

Using the results of these surveys, an in-depth analysis of evaluation was developed by Muñuzuri et al. (2016), and a new proposal was additionally suggested to the retailers. This new proposal was addressed to satisfy all the stakeholders, and used the information collected in the first surveys and conversations. Almost all the retailers share a common problem (difficulty of parking), but their interests are different. Consequently, it was necessary to elaborate a complex measure which looks for the best solution to the global system, but where no one loses.

The measure was based on 3 complementary elements:

- Installation of parking meters with a strict time limit (about $15 \ldots 20 \mathrm{~min}$ ), so a large majority of retailers would be pleased;

- Development of a specific parking point to leave the retailers' own vehicles after the delivery. This point could coincide with the consolidation point shown in Figure 1. Thus, this location would allow the cooperating retailers to park their individual vehicles to enter the city centre with a single van. This aspect would alleviate the lack of parking areas;

- Two new parking spaces in the surrounding pedestrian streets. Even though this aspect is clearly against the pedestrianisation policy followed by the local administration over the last decades, it was the single possibility to satisfy most retailers. However, the use of these spaces would be subject to the participation of retailers in the cooperation scheme. Therefore, this aspect would satisfy the necessity of the six retailers dedicated to fruit and vegetables.

This new combined initiative was presented again to the retailers, using a survey composed of 3 questions:

- Question A: Current situation vs. new proposal;

- Question B: Only regulation of parking areas with parking meter vs. new proposal;

- Question C: Any comments and considerations.

With respect to the new proposed initiative, the results obtained can be summarized as follows. Only 9 of the respondents prefer the current situation, while the rest are willing to test initiatives seeking to improve the situation. Most of the negative responses belong to retailers who use the loading zones as on-street warehouses. As a result, 76 percent of the responders prefer the new proposal. When the choice is only between parking meters and the new proposal, the result changes drastically. In this case, almost all the previously negative responders prefer the new proposal. However, some of the other respondents now prefer the parking meter measure. In an aggregated analysis, $82 \%$ of respondents prefer these combined measures.

In Question C, some retailers expressed their concern about the transfer time between the parking point and the marketplace. As shown in Figure 4, the circulation of particular vehicles around of the city centre is obligatorily done clockwise, and only public transport has a counterclockwise lane enabled. This public transport lane could be open to the participating delivery vehicles through special access permissions issued by the local authorities. This could save $5 \mathrm{~min}$ in the displacement to the parking point, thus saving $50 \%$ of the transfer time. 

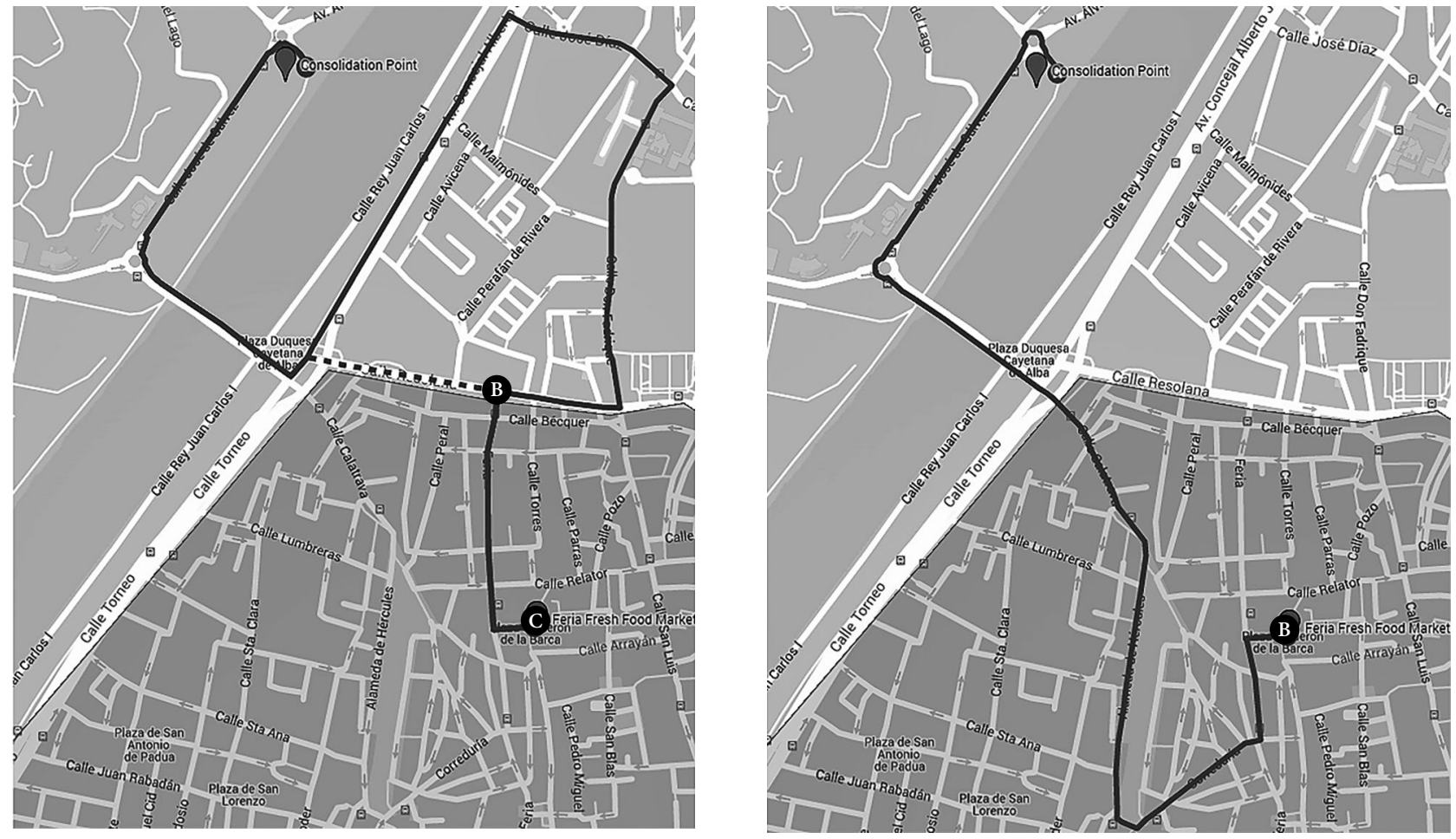

Figure 4. In the left-hand side figure, the current route to the consolidation point is represented by a solid line, and the turning point $B$ and the use of the bus lane with a dashed line; the right-hand side figure represents the way back to the marketplace

\section{Analysis and discussion of results}

Through an exhaustive and deep analysis of the responses obtained in the surveys, we could obtain some interesting insights, apart from the results related to the acceptance or rejection of a specific urban freight policy. First, we can highlight some considerations with respect to the current scenario:

- The current number of loading zones available is enough to serve the Feria Marketplace, if the established rotation is maintained. The existing regulations specify a maximum 15 min period for unloading operations, after which the delivery vehicle has to leave its place to another one. The control of this regulation is a responsibility of the local police. However, its control is rather relaxed in the city;

- The origin of the problem of lack of rotation in loading zones is caused mainly by fruit and vegetable retailers. They arrive earliest in the morning, and park their vehicles in the loading zones all day long. This does not happen only because fruit and vegetable retailers are inconsiderate with the rest, since this is a generalized situation in other similar areas of the city, where retailers keep their vehicles parked in the same place for hours instead of simply unloading the goods and moving their vehicle away.

In this scenario, the result of the analysis highlights some interesting aspects. The initial cooperative scheme is highly refused, but fruit retailers show a stronger opposition, since they have a rather easy life with the current state of affairs. Only the fish retailers consider it a good solution. The preferred solution to the load zone rotation problem should simply consider the enforcement of the existing regulations. Most carriers are clearly in favour of parking meters, since they should free some of the available loading space. However, fruit carriers are strongly opposed to parking meters.

This situation results in the difficulties that arise when trying to implement a cooperative schema in an environment where some stakeholders break the existing regulations. It focuses the interest of the remaining stakeholders on measures aimed at enforcing the existing rules (like parking meters, which prevent fruit and vegetable carriers to park their vehicles in the loading zones during the whole day).

When the combined measure was proposed, more carriers considered cooperation as a viable possibility. However, the stakeholders benefited from the current situation are opposed to any perturbations. However, when stronger regulations are presented as the alternative, they are more responsive to the possibility of cooperating.

Thus, the agitation of the current situation and the necessity to find solutions that do not damage anybody's interests could be a catalyst for the introduction of cooperative schemes. This fact was also supported by fish carriers, all of which used to share vehicles some years ago, when the cost of refrigerated vehicles was higher. Nevertheless, cooperation requires the active participation of the local authorities (Lindholm, Browne 2013) through the enforcement of the rules and the issuing of special permissions. 


\section{Conclusion and future research}

To prevent the rise of transportation costs, increasing congestion and emissions, cooperation initially seems to be an interesting alternative. However, due to the different interests and perceptions, the evaluation of city logistics policies must take into account the different views of the different stakeholder groups, and the fact that each one of these groups makes decisions according to an entirely different set of partial objectives.

In the heavily congested city centre of Seville (Spain), the Feria Fresh Food Marketplace is a typical traditional market, located in the old city centre, where there is significant lack of space and parking facilities. This fact usually causes severe problems in logistics and distribution, resulting in a general consensus about the necessity of taking measures.

This work presented the proposal and assessment of a cooperative scheme for the Feria marketplace. A priori, cooperative deliveries in a fresh food market have a high potential, due to the existence of common providers in wholesale markets and the similarity of working times. To evaluate the possibilities of this measure, we carried out a double survey process. Following a deeper analysis of the responses given to our surveys, we reached two important conclusions: the predisposition to cooperation depends on the degree of satisfaction with the current situation (only when the current situation is changed, some stakeholders are encouraged to cooperate) and the fact that personal relations sometimes have a higher weight than efficiency criteria. These conclusions could be extended to other markets and similar urban freight attractors.

The individuality of the retailers involved is then the main reason behind their rejection of cooperative schemes, which would possibly result cheaper, more sustainable and free from the intervention of the administration. In their place, the only way out for the local authorities in view of the existing conflict in the Marketplace would be the installation of parking meters in the loading zones (which had been incidentally voted by the retailers, in an assembly with a rather low level of participation and consensus) and the establishment of special conditions, such as circulation permissions on the bus lane. These measures were proposed specifically to address the existing problems in the Feria Market. The extrapolation of these specific measures to other Fresh Food Markets requires future research and study of their particular characteristics and stakeholder distribution. However, two aspects are global: local authorities must establish and enforce the necessary regulations to promote cooperation, avoiding the monopolizing of resources, and they must implement mechanisms that make cooperation easier.

In conclusion, although collaboration has a high potential as a logistic solution for the centre of the city, its start-up in a fresh food marketplace requires flexibility on the part of all stakeholders and clear involvement of the local administration.

\section{Acknowledgements}

The authors wish to acknowledge the financial support of project ECOTRANSIT (Ref. TEC2013-47286-C3-3-R) for the completion of this work.

We would like to additionally thank the participants, traders in Feria Marketplace and local authorities, for their time and their willingness to complete the surveys.

\section{References}

Bengtsson, M.; Kock, S. 1999. Cooperation and competition in relationships between competitors in business network, Journal of Business \& Industrial Marketing 14(3): 178-194.

https://doi.org/10.1108/08858629910272184

Chen, Q.; Lin, J.; Kawamura, K. 2012. Comparison of urban cooperative delivery and direct delivery strategies, Transportation Research Record: Journal of the Transportation Research Board 2288: 28-39. https://doi.org/10.3141/2288-04

Cruijssen, F.; Dullaert, W.; Fleuren, H. 2007. Horizontal cooperation in transport and logistics: a literature review, Transportation Journal 46(3): 22-39.

Dablanc, L; Diziain, D.; Levifve, H. 2011. Urban freight consultations in the Paris region, European Transport Research Review 3(1): 47-57. https://doi.org/10.1007/s12544-011-0049-2

EC. 2001. Guidelines on the Applicability of Article 81 of the EC Treaty to Horizontal Cooperation Agreements. 29 p. Available from Internet: https://eur-lex.europa.eu/legal-content/EN/ TXT/PDF/?uri=CELEX:32001Y0106(01)\&from=EN

Forza, C. 2008. Surveys, in C. Karlsson (Ed.). Researching Operations Management, 84-161.

Gammelgaard, B. 2015. The emergence of city logistics: the case of Copenhagen's Citylogistik-kbh, International Journal of Physical Distribution \& Logistics Management 45(4): 333-351. https://doi.org/10.1108/IJPDLM-12-2014-0291

Gonzalez-Feliu, J.; Morana, J.; Salanova Grau, J.-M.; Ma, T.-Y. 2013. Design and scenario assessment for collaborative logistics and freight transport systems, International Journal of Transport Economics 40(2): 207-240.

Gonzalez-Feliu, J.; Salanova, J.-M. 2012. Defining and evaluating collaborative urban freight transportation systems, Procedia Social and Behavioral Sciences 39: 172-183.

https://doi.org/10.1016/j.sbspro.2012.03.099

Jaller, M.; Holguín-Veras, J.; Hodge, S. D. 2013. Parking in the city: challenges for freight traffic, Transportation Research Record: Journal of the Transportation Research Board 2379: 46-56. https://doi.org/10.3141/2379-06

Jaržemskis, A. 2007. Research on public logistics centre as tool for cooperation, Transport 22(1): 50-54.

Karlsson, C. 2008. Researching Operations Management. Routledge. $336 \mathrm{p}$.

Lindholm, M; Browne, M. 2013. Local authority cooperation with urban freight stakeholders: a comparison of partnership approaches, European Journal of Transport and Infrastructure Research 13(1): 20-38.

Marcucci, E.; Gatta, V. 2014. Behavioral modeling of urban freight transport, in J. Gonzalez-Feliu, F. Semet, J.-L. Routhier (Eds.). Sustainable Urban Logistics: Concepts, Methods and Information Systems, 227-243.

https://doi.org/10.1007/978-3-642-31788-0_12

Marcucci, E.; Gatta, V.; Stathopoulos, A.; Valeri, E. 2011. Designing an Efficient Stated Ranking Experiment for Ex-Ante Urban 
Freight Policy Evaluation in a Three Agent Type Context: Retailers, Own-Account and Carriers. 18 p. Available from Internet: http://www.sietitalia.org/wpsiet/WP-SIET-EMarucciVgatta-AStathopoulos-EValeri2011.pdf

Mingardo, G.; Van Wee, B.; Rye, T. 2015. Urban parking policy in Europe: a conceptualization of past and possible future trends, Transportation Research Part A: Policy and Practice 74: 268-281. https://doi.org/10.1016/j.tra.2015.02.005

Muñuzuri, J.; Cortés, P.; Guadix, J.; Onieva, L. 2012. City logistics in Spain: why it might never work, Cities 29(2): 133-141. https://doi.org/10.1016/j.cities.2011.03.004

Muñuzuri, J.; Larrañeta, J.; Onieva, L.; Cortés, P. 2005. Solutions applicable by local administrations for urban logistics improvement, Cities 22(1): 15-28.

https://doi.org/10.1016/j.cities.2004.10.003

Muñuzuri, J.; Onieva, L.; Cortés, P.; Guadix, J. 2016. Stakeholder segmentation: different views inside the carriers group, Transportation Research Procedia 12: 93-104.

https://doi.org/10.1016/j.trpro.2016.02.050

Österle, I; Aditjandra, P. T.; Vaghi, C.; Grea, G.; Zunder, T. H. 2015. The role of a structured stakeholder consultation process within the establishment of a sustainable urban supply chain, Supply Chain Management: an International Journal 20(3): 284-299. https://doi.org/10.1108/SCM-05-2014-0149

Pan, S.; Ballot, E.; Fontane, F.; Hakimi, D. 2014. Environmental and economic issues arising from the pooling of SMEs' supply chains: case study of the food industry in western France, Flexible Services and Manufacturing Journal 26(1-2): 92-118. https://doi.org/10.1007/s10696-012-9162-3

Pomponi, F.; Fratocchi, L.; Tafuri, S. R. 2015. Trust development and horizontal collaboration in logistics: a theory based evolutionary framework, Supply Chain Management: an International Journal 20(1): 83-97. https://doi.org/10.1108/SCM-02-2014-0078

Razzaque, M. A; Sheng, C. C. 1998. Outsourcing of logistics functions: a literature survey, International Journal of Physical Distribution \& Logistics Management 28(2): 89-107. https://doi.org/10.1108/09600039810221667

Saeed, N. 2013. Cooperation among freight forwarders: mode choice and intermodal freight transport, Research in Transportation Economics 42(1): 77-86. https://doi.org/10.1016/j.retrec.2012.11.005

Skjoett-Larsen, T. 2000. Third party logistics - from an interorganizational point of view, International Journal of Physical Distribution \& Logistics Management 30(2): 112-127. https://doi.org/10.1108/09600030010318838

Verlinde, S.; Macharis, C.; Witlox, F. 2012. How to consolidate urban flows of goods without setting up an urban consolidation centre?, Procedia - Social and Behavioral Sciences 39: 687-701. https://doi.org/10.1016/j.sbspro.2012.03.140 